Running Head: RAPPORT AND COMPENSATION

Interactive Effects of Proactive and Reactive

Service Recovery Strategies:

The Case of Rapport and Compensation

Kate Worsfold, Jennifer Worsfold and Graham Bradley

Griffith University

Queensland, Australia 


\title{
Interactive Effects of Proactive and Reactive Service Recovery Strategies: The Case of Rapport and Compensation
}

\author{
Abstract \\ Researchers have recently investigated the efficacy of different strategies for \\ recovering from service failure. This paper reports two studies that test the effects of \\ a reactive recovery strategy (compensation) and a proactive strategy (establishing \\ prior rapport between service provider and customer). These strategies, plus aspects \\ of the service problem, were manipulated using written scenarios. Consistent with \\ predictions based on justice theory and the service recovery literature, customer \\ evaluations were more favourable following high rapport, high compensation, minor \\ service failures, and non-financial losses. Rapport and compensation interacted in a \\ manner consistent with the "fair process" effect, although this interaction varied with \\ failure severity and the dependent variable studied. The research underscores the \\ importance of relationship-building in the management of service failures.
}


As service industries occupy expanding proportions of most of the world's economies, research is increasingly directed towards understanding consumer expectations, perceptions and evaluations of service delivery (Bateson \& Hui, 1992; Hui, Zhao, Fan, \& Au, 2004; Smith, Bolton, \& Wagner, 1999). Researchers have recognised the near inevitability of occasional lapses in service quality (Goodwin \& Ross, 1992), and have sought to identify ways in which service failures are best managed. This current research contributes to knowledge of service failure and recovery processes.

Strategies aimed at mitigating the effects of service failure can be divided into two classes, proactive and reactive. Both types of strategies have a similar aim in that they attempt to moderate the negative consequences of service failure (DeWitt \& Brady, 2003). Proactive strategies operate before a breakdown in service occurs, whilst reactive strategies are enacted after service failure. Examples of the former include the provision of service quality guarantees, offering choice to customers prior to service delivery, and attempts to foster rapport between customers and service providers. Examples of reactive strategies include the provision of post-failure apologies, explanations and offers of compensation.

In the current research, one example of each type of strategy was selected for study. The selected proactive strategy was service provider-customer rapport, as evidenced by the existence of an enjoyable interaction, and the establishment of a bond, between customer and service provider (Gremler \& Gwinner, 2000). An offer of financial compensation was selected as the reactive strategy. Compensation forms part of the 
outcome of a service exchange, whilst rapport is part of the process by which outcomes are determined.

Most past research has examined the effects of service recovery strategies on two main outcomes: customer satisfaction and customer repatronage (or loyalty) intentions. The research has less often investigated effects on customer complaint behaviors. However, anecdotal evidence (e.g., Harari, 1992) indicates that perhaps 70 to $95 \%$ of customers who experience a dissatisfying service encounter do not bother complaining. Blodgett, Hill, and Tax (1995), DeWitt and Brady (2003) and others have argued that complaint behavior is desirable from the perspective of service firms: companies should encourage dissatisfied consumers to voice their complaints so that problems can be rectified and customers do not switch firms. It is, therefore, important to investigate the conditions that encourage and discourage complaint behavior. Thus, the current studies investigated three customer outcomes: satisfaction, repatronage, and complaint intentions.

\section{Compensation}

Financial compensation is the most widely researched aspect of service recovery (Davidow, 2003). A number of social psychological theories, including theories of social exchange, equity and distributive justice (e.g., Adams, 1965; Thibaut \& Walker, 1975), predict that the provision of compensation will assist in returning an aggrieved party to a satisfied state. The equity principle, for example, defines a fair exchange as one in which all parties receive outcomes in proportion to their contributions. In a service failure context, if the compensation offered is 
proportionate to the loss due to the service failure, then the exchange will be perceived as fair, and positive customer evaluations should ensue. Ample empirical evidence supports this prediction: compensation in a variety of forms - discounts, token gifts, vouchers, room upgrades, and so on - has been shown to positively impact levels of post-failure customer satisfaction with, and likely re-use of, a range of services (Conlon \& Murray, 1996; Davidow, 2003; Goodwin \& Ross, 1992; Sparks \& McColl-Kennedy, 2001).

\section{Rapport and the Importance of Human Interaction}

Since service encounters are essentially social interactions, they provide scope for building strong relationships with customers. Customers may derive benefits not only from the core service provided by a firm but also from the personal recognition and social support resulting from their relationships with service staff. Consistent with theories of interactional justice (e.g., Bies \& Moag, 1986), the provision of rapport is likely to enhance customers' sense that they are being treated with respect and courtesy, and hence that the service exchange is a fair one. Supporting this reasoning, a large body of research (for a review, see Gremler \& Gwinner, 2000) has demonstrated that, in service exchanges delivered without failure, rapport has a positive effect on satisfaction and repatronage intentions. More recently, DeWitt and Brady (2003) found that the prior existence of customer-provider rapport also reduces the negative effects of service failures. It seems that the relational benefits customers derive from past encounters with service organizations help to protect the organization from the negative consequences of current service failures. The finding is consistent with the brand equity effect observed by Tax, Brown, and 
Chandrashekaran (1998): that is, one negative encounter in an otherwise positive relationship does little to change customers' overall trust in and commitment to the service organization.

DeWitt and Brady (2003) tested the hypothesis that, compared to customers who lacked rapport with the service provider, customers who had high rapport would be more likely to complain after a service failure. Findings in both of their studies failed to confirm this prediction. In their first study, there was no difference in complaint intentions between individuals who had high and low rapport, and, in their second study, high rapport individuals were significantly less likely to complain than were low rapport customers. If (as was argued previously) complaint behavior is a desired outcome from the organization's viewpoint, DeWitt and Brady's results thus suggest that the benefits of using rapport may be partially offset by lowered customer complaint intentions. The current research aimed to further examine the relationship between rapport and complaint intentions.

To summarize, both theory and research lead to the predictions that compensation (a reactive, outcome variable) and rapport (a proactive, process variable) have positive effects on customer satisfaction and repatronage intentions. Effects on complaint behavior have been less thoroughly investigated, and are less certain.

\section{Rapport and Compensation Combined}

While previous research has demonstrated main effects for compensation and rapport, no prior study has examined the interactive effects of these variables. Research by Blodgett, Wakefield, and Barnes (1995), Sparks and Callan (1996) and others has 
shown that customer evaluations of the tangible outcomes they receive after service failure depend upon other, less tangible aspects of the service exchange. More specifically, outcome variables such as compensation have been shown to interact with process variables (for example, the manner in which the compensation was offered) to determine customer reactions (Davidow, 2000; Sparks \& McCollKennedy, 2001; Smith et al., 1999). Given the wealth of evidence documenting the existence of such interactive effects in relation to such process variables as service provider-attentiveness, -concern, and -promptness, similar interactive effects were predicted to occur in relation to rapport.

The interaction between compensation (or any other outcome variable) and rapport (or other process variable) may take one of two distinctive forms. On the one hand, the negative effects of a poor outcome may be buffered, or "softened", if the exchange process is perceived to be a fair and favourable one. For example, when customers receive inadequate compensation for a service failure (and hence have perceptions of low distributive justice), their dissatisfaction may be reduced by treatment characterised by high levels of courtesy and respect (hence, high interactional justice). This tendency to tolerate poor outcomes if they are dispensed in a just manner is referred to as the "fair process" effect (see, e.g., Collie, Bradley, \& Sparks, 2002; van den Bos, Bruins, Wilke, \& Dronkert, 1999). Under this effect, levels of rapport make little difference to evaluations when customers are generously compensated, but make a substantial difference as compensation levels diminish.

On the other hand, rapport may have an enhancing, rather than a buffering, effect. According to this hypothesis, rapport and compensation (or any other pair of 
strategies that enhance interactional and distributive justice, respectively) act synergistically to elicit disproportionately favourable customer responses. Thus, the difference between high and low rapport conditions are greatest, not when compensation is low, but when it is high. Such an enhancing effect is consistent with the two-factor theory of customer satisfaction proposed by Maddox (1981) and Swan and Combs (1976). This perspective suggests that, whilst both compensation and rapport may be necessary for customer satisfaction, neither, by itself, is sufficient. Satisfaction increases (exponentially) only when both are present. Studies by Blodgett et al. (1995), Blodgett, Hill, and Tax (1997), and Tax et al. (1998) are supportive of such an enhancing effect. These researchers found that when compensation was high, the impact of process or interactional justice variables upon customer evaluations (e.g., satisfaction and repatronage) was greater than when less compensation was provided.

We predicted a Rapport x Compensation interaction, and set out to test these rival predictions as to the form the interaction takes. Hui et al. (2004) have recently conducted two studies examining this issue. They reported mixed findings, with the nature of the effect - buffering or enhancing - depending on other variables. The current research extends Hui et al.'s work by investigating whether a process factor occurring prior to service failure buffers or enhances (or makes no difference to) the effects of a post-failure recovery strategy. In other words, our research addresses the broader question: do proactive and reactive service recovery strategies interact in ways that are congruent with the fair process effect or with predictions derived from two-factor theory? 


\section{Service Context Variables}

Past research has demonstrated that the impact of service recovery strategies is contingent upon a variety of contextual factors such as the sector of industry in which the failure occurs, the nature and criticality of the service, the type of service failure, and the severity of this failure (see, e.g., Davidow, 2003; Webster \& Sundaram, 1998). It is possible that some of these contextual variables may not only qualify the simple effects of rapport and compensation, but also act as higher order moderators of any rapport $\mathrm{x}$ compensation interaction effect.

In the current research, the role of two such contextual factors was examined. Study 1 investigated the impact of type of service failure, whilst Study 2 examined the impact of severity of failure. In Study 1, the problem involved either a financial loss (a service was paid for but found to be unusable) or a non-financial loss (the delivery of the requested service was delayed). Research by Smith et al. (1999) has shown that customers in service failure/recovery encounters prefer to receive resources matching the type of loss they experienced. For example, if customers experience financial loss, they expect to be compensated financially. If service failure leads to a loss of a social resource (e.g., if inconvenienced), customers prefer to receive psychological, social or symbolic recognition as part of the recovery strategy. Smith et. al. refer to this as the "matching hypothesis". Therefore, in Study 1 it was expected that for service failures involving a financial loss, level of compensation would have a stronger influence on customer evaluations than would level of rapport, whereas in situations of nonfinancial loss, rapport would have the stronger effect. 
Rationale and Aims of Current Research

The impetus for this research came from several sources. In part, it was derived from a call in a review of the literature (Davidow, 2003) for more research into possible interactions between service recovery strategies and the contexts in which they occur. Our research also gained impetus from the work of DeWitt and Brady (2003), which drew attention to the possibility that the limited success of many service recovery attempts may be due to an over-reliance upon reactive strategies - ones that are performed too late in the service exchange to mitigate the damage caused by the failure. The studies by Sparks and McColl-Kennedy (2001) and Hui et al. (2004) demonstrating complex interactions between outcome and process variables also provided stimulus for the current research.

Our research investigated the main and interactive effects on customer evaluations of a proactive strategy (rapport) and a reactive strategy (compensation) We used written scenarios of service failures to test our predictions. The Study 1 service scenario was set in DVD hire outlet, whilst the Study 2 scenario took place in a restaurant. These particular settings (and the associated service problems) were selected for two reasons. First, past research (e.g., Smith et al., 1999; Tax et al., 1998) has shown that service failures are commonly experienced in the delivery of hospitality and recreational services. In Tax et al.'s study, for example, customer complaints were received more often in relation to restaurants than to any other service sector. Similarly, the types of service breakdowns specified in the scenarios (one delayed and one unavailable service) are commonly reported in real life, and have frequently been used in past studies of service failure (e.g., Levsque \& McDougall, 2000; Matilla \& 
Patterson, 2004; see also Sparks, 2001). The second reason for selecting these scenarios was evidence from our pilot studies indicating that the majority of potential respondents frequently use these services. This familiarity with the services was expected to enable participants to readily adopt the role of the customer in each scenario.

Our research tested rival hypotheses as to the form of any Rapport $\mathrm{x}$ Compensation interaction effects, and explored the possibility that service failure contextual variables act as higher-order moderators of these effects. We also investigated whether these effects differ with the criterion used to assess recovery success. Both studies included measures of three dependent variables (DVs): customer satisfaction, repatronage and complaint intentions. Many past studies have examined a subset of these constructs, but there is merit in assessing all three outcomes because of the likelihood that they are imperfectly correlated. For example, dissatisfied customers do not necessarily complain, and complaining customers do not necessarily switch firms. Similarly, a particular recover strategy may, for example, "buy" customers' silence, but not their satisfaction or future loyalty.

The following hypotheses were tested in both studies:

H1. Compared to lower levels of compensation, higher compensation leads to greater (a) customer satisfaction and (b) customer repatronage intentions.

H2. Compared to lower levels of rapport, higher rapport leads to greater (a) satisfaction and (b) repatronage.

H3. Compensation and rapport interactively affect levels of (a) satisfaction and (b) repatronage. 
No predictions were made as to the effects of the IVs on complaint intentions, or the direction of the Compensation x Rapport interaction effect.

In Study 1, it was further predicted that:

H4. The relative size of the effects associated with compensation and rapport vary with type of service failure. Specifically, following failures involving financial loss, compensation has a stronger effect on customer evaluations than does rapport, whereas in situations of non-financial loss, rapport has the stronger effect.

\section{Study 1}

Study 1 used written service scenarios describing a service transaction in a DVD hire shop. A 2 (compensation: high vs. low) x 2 (rapport: high vs. low) x 2 (service failure type: financial vs. non-financial) independent groups factorial design was employed, with three dependent variables: satisfaction, repatronage intentions, and complaint intentions.

\section{Method}

\section{Participants}

A convenience sample of 180 undergraduate students (130 females, 50 males) at a public university in Queensland, Australia, participated in return for course credit. Mean age of participants was 24.4 years $(S D=7.71)$. Mean frequency of hiring DVD's was 3.45 times per month $(S D=2.66)$. Prior to the main study, two pilot tests 
were conducted, involving convenience samples of undergraduate students (Ns $=36$ and 23 , respectively).

\section{Materials}

Scenarios. Eight written versions of a scenario describing a service failure were developed using prior research (e.g., Blodgett et al., 1997) as a foundation, and refined in the two pilot studies. The scenario versions were identical except for the manipulation of the independent variables. In all versions, service attendant age and gender were not specified and the DVD store was an independently-run outlet.

Independent variables. In half of the scenarios, the product was described as defective, and a financial loss was incurred because the customer discovered the problem after paying for the (faulty) DVD and watching a third of it. In the nonfinancial scenario, the customer booked the DVD by prior phone call but was kept waiting 20 minutes whilst the employee searched for the pre-booked DVD. Consistent with the model of rapport developed by Gremler and Gwinner (2000), the high rapport scenarios included a description of an enjoyable interaction and personal connection between the customer and service attendant, whereas the interaction was not described in these terms in the low rapport scenario. Thus, in the high rapport condition, the customer frequented the store, knew the service provider's name and had interests in common with this employee. Compensation was manipulated in terms of a reduction in the cost of the next DVD hire - either no charge (high compensation) or a $50 \%$ discount (low compensation) on the next movie hire. 
Dependent measures. The DVs were measured using adaptations of existing scales. The satisfaction scale comprised six items, including five from Gremler and Gwinner (2000), for example: "Based on what I read about this video store, I am very satisfied with the service it provides". Repatronage intentions was measured by four items, three of which were from Blodgett et al. (1997), for example: "What is the likelihood that you would hire a movie from this video store in future?". Complaint intentions was measured using five items based on DeWitt and Brady (2003), for example, "Given the circumstances, I would complain to the video store employee". Responses to all items (on 7-point scales, ranging from 1 = strongly disagree / very unlikely to 7 = strongly agree / very likely) were averaged to form composite scales.

Manipulation checks. The manipulation of all IVs was assessed using multi-item scales. All items required responses on the same 7-point response continuum used to measure the DVs (with the exception of one compensation item). Rapport was tested by six items from Gremler and Gwinner (2000). The manipulation of problem type and compensation were each assessed via three items (e.g., "This service failure has cost me money", and "The compensation I received was high", respectively) that were developed for this study ( $\alpha=.89$ and $\alpha=.77$, respectively). Realism of scenarios was assessed by a five-item believability scale from Willson and McNamara (1982).

\section{Procedure}

Data were collected in small non-interacting groups of $10-30$ students. After reading an information sheet, participants were randomly assigned to one of the eight conditions. Participants read one version of the scenario and responded to the 
questions that followed whilst imagining they were the customer described in the scenario. Sessions lasted approximately 20 minutes.

Results

One case was deleted from the data set because of missing data on some items measuring the dependent variables (final $\mathrm{N}=179$ ). Responses to the manipulation check scales indicated that all variables were manipulated as intended, and the scenarios were rated as believable by all participants. Perceived failure severity did not vary between conditions.

Descriptive statistics and correlations between the dependent variables are given in Table 1. All measures displayed adequate reliability.

Insert Table 1 about here

The data were assessed for violations of the assumptions underlying multivariate analysis of variance (MANOVA). Because Box's M was significant, Pillai's criterion was used. All other MANOVA assumptions were met.

A 2 (rapport) x 2 (compensation) x 2 (problem type) between-subjects MANOVA was conducted with satisfaction, repatronage intentions, and complaint intentions as the dependent variables. Multivariate effects were assessed using a $p$-value of .05. 
To control for Type 1 errors, all univariate tests were assessed using a Bonferroni correction for three DVs $(\alpha=.0167)$.

As can be seen from the MANOVA results summarized in Table 2, the three-way interaction of rapport, compensation and problem type was not significant.

MANOVA did, however, reveal significant multivariate interactions between rapport and compensation, and between problem type and rapport, but not between problem type and compensation.

Insert Table 2 about here

Of most interest in this study was the Rapport $\mathrm{x}$ Compensation interaction. Univariate tests revealed this interaction had a significant effect on satisfaction only. Simple effects showed that, regardless of whether compensation was low or high, participants in the high rapport condition expressed significantly higher satisfaction than did those in the low rapport condition (low compensation: $M \mathrm{~s}=3.59$ and 5.31, respectively, $t$ $(1,176)=8.01, p<.0005$; high compensation: $M \mathrm{~s}=4.49$ and 5.44, respectively, $t(1$, $176)=4.44, p<.0005)$. Although both of these planned contrasts were significant, the difference between high and low rapport was greater in the low $\left(\eta^{2}=.266\right)$ than in the high $\left(\eta^{2}=.066\right)$ compensation condition. Thus, there was evidence that the major impact of rapport was to buffer the damaging effect of low levels of compensation, a finding that is consistent with the fair process effect. 
Univariate tests showed that the Rapport x Problem Type interaction was significant on satisfaction, and repatronage intentions, but not significant on complaint intentions. Contrary to the "matching hypothesis", however, the effects of rapport were greater than those of compensation on all three consumer responses in both the financial and the non-financial conditions.

Finally, significant multivariate main effects were obtained for each of rapport, compensation, and problem type. Univariate results showed significant main effects for all three experimental variables on each of the dependent variables. Thus, compared to the rival conditions, customers were more satisfied, more intent on repatronage, and less likely to complain under conditions of high rapport, high compensation, and non-financial loss.

\section{Study 2}

Study 1 demonstrated that post-failure customer evaluations were more favourable under conditions of high (versus low) rapport, high (versus low) compensation, and non-financial (versus financial) loss. The study further demonstrated that the adverse effects of low compensation on customer satisfaction were buffered by high levels of rapport. This interactive effect was evidenced in both financial and non-financial service failure situations.

Study 2 sought to partially replicate and extend the first study. Given evidence as to the situational-specificity of the efficacy of many service recovery strategies (e.g., Smith et al., 1999), the possibility exists that the Rapport x Compensation "fair 
process" effect observed in Study 1 may be unique to some aspect of the sample, service context and/or service problem used in that study. The second study thus assessed the robustness of this effect in an independent sample using a different service scenario.

Study 2 differed from the first study in a further way. Since Study 1 found that the Rapport x Compensation interaction effect did not change across two types of service problems (i.e., the three-way interaction was not significant), the variable of problem type was substituted in Study 2 with another service context variable, namely, severity of service failure. There exists ample evidence (e.g., Conlon \& Murray, 1996; Widmier \& Jackson, 2002) as to the effects that failure severity has upon customer evaluations: increases in the size of a service failure have consistently been associated with reductions in customer satisfaction and repatronage.

No previous study has investigated the interplay between failure severity and rapport. However, based on evidence reviewed previously of the interdependent effects of outcome and process variables, it was predicted that the outcome variable, failure severity, and the process variable, rapport, will interactively impact customer evaluations. Whilst this interaction could again take one of two forms (buffering or enhancing), evidence from DeWitt and Brady's (2003) research involving service failures of differing levels of severity suggests that differences between high and low rapport are likely to be more marked when failure severity is high rather than low. Thus, rapport acts to buffer the adverse effects of negative outcomes in a manner consistent with the fair process effect. 
Furthermore, interest in our second study focused on the possibility of a Rapport $\mathrm{x}$ Compensation x Severity interaction. For example, a fair process effect may be evident under conditions of low, but not high, failure severity. Such a three-way interactive effect could apply because there may be limits to the extent to which favourable processes can make up for poor outcomes: as problem severity increases beyond some threshold, customers - even those who have high rapport with the service provider - may no longer tolerate a failure to compensate.

Thus, in addition to providing a further test of hypotheses 1-3, Study 2 tested the following predictions:

H5. Compared to higher levels of failure severity, lower severity leads to greater (a) satisfaction and (b) repatronage intentions.

H6. Rapport and severity interactively affect levels of (a) satisfaction and (b) repatronage, with the differences between rapport conditions being more marked following high than low severity failures.

H7. Under conditions of low but not high failure severity, compensation and rapport interactively affect (a) satisfaction and (b) repatronage.

Method

The Study 2 sample comprised 182 undergraduate students (147 females, 35 males) drawn in the same way from the same population as for Study 1. Participants' mean age was 23.21 years $(S D=6.69)$. A 2 (rapport: high vs. low) x 2 (compensation: absent vs. present) x 2 (failure severity: high vs. low) independent groups design was employed using the same three dependent variables as in Study 1. 
Drawing on the work of Smith et al. (1999), eight versions of a written service failure scenario were developed and refined in two pilot studies. All versions were set in a restaurant with the service employee's age and gender ambiguous. All situations involved a non-financial loss to the customer. In low failure severity situations, a failure occurs due to the unavailability of a selected main meal. For high severity situations, the customer selects a further main meal which is also unavailable. Compensation was operationalized as the presence or absence of a $20 \%$ discount on the current bill. Rapport was operationalized as in Study 1. The manipulation of failure severity was assessed via four items (e.g., "There was a serious failure of this service") developed for this study $(\alpha=.81)$. The remaining manipulation checks and the believability measures were similar to those used in Study 1, whilst the dependent measures were identical to those previously used. Data collection procedures were as described for Study 1.

Results

Three cases were deleted due to missing data (final $\mathrm{N}=179$ ). All variables were shown to be manipulated as intended, and all scenarios were judged to be highly believable. Table 3 gives descriptive statistics and correlations between dependent variables. All three dependent measures were highly reliable.

Insert Table 3 about here 
Results of the MANOVA are summarized in Table 4. As can be seen, there was a significant three-way multivariate interaction of Rapport x Compensation $\mathrm{x}$ Failure Severity. Univariate tests revealed that this effect was significant on repatronage, and on complaint intentions, but not on satisfaction. Details of the univariate effect on repatronage are reported prior to that on complaints.

Insert Table 4 about here

In the low failure severity condition, regardless of whether compensation was absent or present, high rapport participants ( $M \mathrm{~s}=5.72$ and 6.20, respectively) expressed greater repatronage intentions than those with low rapport $(M \mathrm{~s}=4.97$ and 5.64, respectively), $t(41)=3.01, p=.005, \eta^{2}=.179$; and $t(43)=3.77, p<.0005, \eta^{2}=.248$. In contrast, in the high failure severity condition, when no compensation was given, high rapport participants $(M=4.90)$ had greater repatronage intentions compared to low rapport subjects $(M=2.95), t(44)=11.03, p<.0005, \eta^{2}=.734$, whereas when the $20 \%$ discount was provided, repatronage intentions were not significantly different between high $(M=5.06)$ and low rapport participants $(M=4.51), t(43)=$ $1.64, p=.109, \eta^{2}=.059$. Thus, a fair process effect on repatronage was evident under conditions of high, but not low, failure severity.

The three-way interaction on complaint intentions revealed that, in the low failure severity condition, when no compensation was provided, no significant differences were found between those with low $(M=2.29)$ compared to high rapport $(M=2.42), t$ $(42)=-.52 ; p=.607, \eta^{2}=.006$. However, when compensation was provided, high 
rapport participants $(M=1.76)$ were significantly less likely to complain compared to those with low rapport $(M=2.53), t(43)=2.83, p=.008, \eta^{2}=.157$. For the high failure severity condition, regardless of whether compensation was absent or present, no significant differences were found between participants with low $(M \mathrm{~s}=3.59$ and 3.02 , respectively) and high rapport $(M s=3.46$ and 3.45, respectively), $t(42)=.53, p$ $=.602, \eta^{2}=.007$, and $t(44)=-1.42, p=.162, \eta^{2}=.044$, respectively. Thus, only under conditions of low failure severity and compensation-present did customers with high rapport complain less than did those with low rapport.

Two of the three two-way multivariate interaction effects were significant: rapport interacted with compensation, and with failure severity, whilst the Failure Severity $\mathrm{x}$ Compensation interaction was not significant. Univariate tests revealed that the Rapport x Compensation and Rapport x Severity interactions were significant $(p<$ .0167) on repatronage only. Since these effects are qualified by the three-way interaction reported above, they are described in summary terms only. In relation to the Rapport $\mathrm{x}$ Compensation interaction, the difference in mean repatronage between high and low rapport was larger in the compensation absent, than in the compensation present, condition. In other words, consistent with the fair process effect, rapport had a buffering effect on the compensation $\rightarrow$ repatronage relationship. In relation to the Rapport x Severity interaction, regardless of failure severity, repatronage intentions were greater when there was high rather than low rapport, although the magnitude of this difference was greater under conditions of high (vs. low) failure severity. In other words, rapport buffered the adverse impact of a severe service failure on repatronage intentions. 
Whilst the Rapport x Compensation effect was not significant on satisfaction at the $p$ $<.0167$ level, the non-significant trend $(p=.044)$ in the satisfaction data was the same as that found for repatronage, that is, rapport buffered the adverse effects of an uncompensated service failure.

Finally, as was the case in Study 1, MANOVA revealed significant multivariate main effects for all three independent variables. As expected, compared to the rival conditions, customer satisfaction and repatronage intentions were greater under conditions of high rapport, compensation present, and low severity. Failure severity, but not rapport or compensation, impacted complaint intentions: participants indicated a greater likelihood of complaining under conditions of more severe failure $(\mathrm{M}=$ 3.37) than less severe service failure $(M=2.25)$.

\section{General Discussion}

The aim of the current research was to explore the main and interactive effects of rapport, compensation and two service failure variables (type and severity) upon customer satisfaction, repatronage, and complaint intentions. The study is unique in examining whether proactive (e.g., rapport) and reactive (e.g., compensation) service recovery strategies impact interactively upon customer evaluations. Two rival hypotheses were proposed regarding the likely form of this interaction, and interest focused not only on which of these forms better describes the interaction, but also on whether this relationship holds across different dimensions of the service failure experience. 
Consistent with findings from past research, and hypotheses 1, 2 and 5, main effects on customer responses were found for each of rapport, compensation, and severity of service failure. In both studies, rapport explained more variance in satisfaction and repatronage intentions than did compensation. In Study 1, the existence of rapport and high levels of compensation independently reduced participant likelihood of complaining. These effects were not replicated in Study 2. The discrepancy in the two studies' results pertaining to rapport can perhaps be explained by the greater likelihood that rapport would have a complaint-deterring effect in the context of prolonged (e.g., an evening at a restaurant), as opposed to brief (e.g., DVD hire), service encounters. The discrepant finding in relation to compensation may be due to the different levels of compensation provided in the two studies: offering the next service free of charge (Study 1) may "buy" more silence from participants than does an offer of $20 \%$ discount on the current bill (Study 2), because the former offer, more so than the latter, neutralizes the damage resulting from the service failure.

In both studies, rapport interacted with the manipulated dimension of the service failure. In Study 1, there was a significant interaction between rapport and problem type. However, contrary to hypothesis 4 , there was no evidence to support the prediction that organizational responses to service failure work best when "matched" with the type of loss incurred. Rather, the effect of rapport on all three consumer responses was greater than that of compensation regardless of whether the loss was financial or non-financial. In Study 2, consistent with hypothesis 6, the interaction of rapport and failure severity significantly affected repatronage. This finding is consistent with the fair process effect: rapport (the process variable) had a greater 
buffering effect when the outcome was poor (i.e., the service failure was severe) than when it was not.

In both studies, as predicted in hypothesis 3, significant interactive effects of rapport and compensation were obtained. Tests were conducted to determine the extent to which rapport buffered the (damaging) effects of low compensation, as opposed to enhancing the (beneficial) effects of high compensation. In Study 1, the interaction of rapport and compensation significantly affected satisfaction, but not the other DVs. Consistent with past research that assessed perceptions of interactional and distributive justice and the fair process effect (e.g., van den Bos et al., 1999), rapport was shown to have a buffering effect when customers were faced with a poor outcome (i.e., a service failure followed by low compensation). The three-way interaction with service problem type was not significant, indicating that this effect occurred regardless of whether the service failure involved a financial or a non-financial loss.

In Study 2, the Rapport x Compensation interaction had a substantial impact upon repatronage intentions and the pattern of group means once again indicated a buffering ("fair process") effect. However, this effect was qualified by a significant three-way interaction. Specifically, it was found that only when the service failure was severe did the combination of high rapport and no offer of compensation lead to high levels of intended repatronage. Thus, the direction of this three-way interaction was contrary to that predicted in hypothesis 7: rather than the fair process effect operating only below an unspecified level of failure severity, the effect was found to apply only above a lower threshold of severity. The finding is interesting and deserving of further research attention. Perhaps the true relationship is curvilinear, 
with no fair process effect operating when service failures are trivial (because repatronage is not threatened by such events) or when they are very severe (because no amount of rapport can redeem such a situation). Under this hypothesis, a fair process effect is evident only at intermediate levels of failure severity because only under such circumstances is rapport both necessary and sufficient to offset the adverse impact of a poor outcome.

In Study 2 there was also a significant three-way interaction on complaint intentions. High rapport participants were no more or less likely to complain than those experiencing low rapport, except when high compensation was provided after a low severity failure. In this condition only, high rapport individuals complained less than those with low rapport. The finding suggests a caution may be necessary in interpreting the main effects on complaint intentions observed in Study 1. In particular, the Study 1 finding that rapport reduces complaint behavior may need to be qualified by an acknowledgement of the possibility that rapport acts as a complaint deterrent only in situations of low service failure severity coupled with high compensation. Given that service firms may wish to encourage, rather than discourage, critical feedback from aggrieved customers, the current findings suggest that service providers who have high levels of rapport with their customers should avoid over-compensating these customers for minor service failures.

\section{Limitations}

This study required participants to read and imagine they were experiencing a hypothetical service scenario. The scenario method has been used effectively in 
previous research on service encounters (e.g., Smith et al., 1999), because of its advantages over other methods in terms of feasibility, economy and the ethics of research. However, the possibility of limitations to the realism of scenarios must be acknowledged. While believability ratings indicated that participants found the current set of scenarios realistic, it cannot be said with certainty that the same results would have been found if a field study had been conducted. Findings from this research are limited to the service contexts and problem types studied. Since the samples comprised Australian university students only, generalizations to other populations must be made with caution. Finally, the studies were limited by sample sizes that fell short of levels required to detect small to moderate effects with $80 \%$ power (Cohen, 1988; see also Hair et al., 2006, pp. 416-419). Future research should replicate the current studies using samples that comprise at least 30 participants per experimental condition.

\section{Implications \& Future Research Directions}

At a theoretical level, the research has increased our understanding of the operation of the fair process effect by showing that good processes occurring prior to service failures can buffer the damaging effects of poor outcomes. Future research could explore whether other proactive strategies (e.g., offering customers choice over the mode of service delivery) have similar effects. The current findings were not consistent with predictions based on Swan and Combs 's (1976) two-factor theory of customer satisfaction of a Rapport x Compensation enhancing effect. The findings were also contrary to those of Hui et al. (2004) who reported a buffering effect when service outcomes were uncertain, and an enhancing effect when they were certain. 
The scenarios used in the current studies were explicit as to the outcome received by each customer, yet, despite this certainty, there was no evidence of rapport having an enhancing effect on compensation. This discrepancy between Hui et al.'s findings and those obtained in the current research is possibly due to the use of different service outcome and service process variables.

More practically, the findings point to the potential value to service organizations of customer-employee rapport. In highly competitive service industries, it may often be too late to positively influence customer evaluations after a service failure has occurred. The current finding of main effects associated with rapport suggest that this proactive approach may effectively control damage associated with subsequent service failure. The finding that rapport explained more variance in satisfaction and repatronage intentions than did compensation suggests that it may even be the preferred strategy. Furthermore, the finding that rapport reduced adverse outcomes when minimal compensation was offered suggests that organizations can plausibly achieve savings by substituting compensation pay-outs with high levels of customer rapport. If replicated in future studies, a case can be made for organizations investing greater resources into the development of their employees' rapport-building skills. Service firms could implement training programs that emphasize the acquisition of interpersonal skills via role plays of service failure situations. Similarly, recruitment practices could ensure that employees have the necessary skills and/or personality to initiate, sustain and enhance rapport.

Our findings also suggest the need for a multi-pronged (pre and post-failure) strategy to enhance customer service. The existence of interactive effects involving problem 
type/severity and service recovery strategy implies that businesses should not employ a "one size fits all" approach to service recovery. Rather, "service smart" organizations should implement policies to enable flexible recovery at the front-line. Given that complaint-deterring effects were associated with rapport in one experimental condition, organizations may need to desist from over-compensating for failures in such circumstances, and implement strategies to inform customers that complaint behavior will not result in negative repercussions for staff.

\section{Conclusion}

This research provides further evidence of the complexities of customer evaluations of service failure and recovery. In our two studies, rapport was shown to have a buffering effect on the relationship between compensation and customer evaluations. While financially compensating customers seems an obvious service recovery strategy, this may not always be affordable, and may not always be the most effective approach. Our research suggests that using a proactive strategy such as rapport may be an effective way to avoid loss of business due to service failure. Caution, nonetheless, is required, as the significant interactions between rapport, compensation and the service problem variables observed in this research demonstrate the contextual sensitivities of these service recovery strategies. 


\section{References}

Adams, J. S. (1965). Inequity in social exchange. In L. Berkowitz (Ed.), Advances in experimental social psychology. Vol. 2. (pp. 267-299). New York: Academic Press.

Bateson, J. E. G., \& Hui, M.K. (1992). The ecological validity of photographic slides and videotapes in simulating the service setting. Journal of Consumer Research, 19, 271-281.

Bies, R. J., \& Moag, J. S. (1986). Interaction justice: Communication criteria of fairness. In R. Lewicki, B. Sheppard, \& B.H. Bazerman (Eds.), Research on negotiation in organizations (pp.43-55). Greenwich, CT: JAI Press.

Blodgett, J. Wakefield, K., \& Barnes, J. (1995). The effects of distributive, procedural and interactional justice on postcomplaint behavior. Journal of Retailing, 73, $185-210$.

Blodgett, J. G., Hill, D. J., \& Tax, S. S. (1997). The effects of distributive, procedural and interactional justice on postcomplaint behavior. Journal of Retailing, 73, $185-210$.

Cohen, J. (1988). Statistical power analysis for the behavioral sciences $\left(2^{\text {nd }}\right.$ ed.). Hillsdale, New Jersey: Lawrence Erlbaum Associates.

Collie, T. A., Bradley, G. L. \& Sparks, B. A. (2002). Fair process revisited: Differential effects of interactional and procedural justice in the presence of social comparison equity information. Journal of Experimental Social Psychology, 38, 545-555. 
Conlon, D. E., \& Murray, N. M. (1996). Customer perceptions of corporate responses to product complaints: The role of explanations. Academy of Management Journal, 39(4), 1040-1056.

Davidow, M. (2000). The bottom line impact of organizational responses to customer complaints. Journal of Hospitality and Tourism Research, 24(4), 473-490.

Davidow, M. (2003). Organizational responses to customer complaints: What works and what doesn't. Journal of Service Research, 5(3), 225-250.

DeWitt, T., \& Brady, M. K. (2003). Rethinking service recovery strategies. Journal of Service Research, 6, 193-207.

Goodwin, C., \& Ross, I. (1992). Consumer responses to service failures: Influence of procedural and interactional fairness perceptions. Journal of Business Research, 25, 149-163.

Gremler, D. D., \& Gwinner, K. P. (2000). Customer-employee rapport in service relationships. Journal of Service Research, 3, 82-104.

Hair, J. F., Black, W. C., Babin, B. J., Anderson, R. E., \& Tatham, R. L. C. (2006). Multivariate data analysis ( $6^{\text {th }}$ ed.). Englewood Cliffs, New Jersey: PrenticeHall.

Harari, O. (1992). Thank heaven for complainers. Management Review, 81, 59-60.

Hui, M. K., Zhao, X., Fan, X., \& Au, K. (2004). When does the service process matter? A test of two competing theories. Journal of Consumer Research, 31, $465-475$.

Maddox, R. N. (1981). Two-factor theory and consumer satisfaction: replication and extension. Journal of Consumer Research, 8(1), 97-102.

Smith, A., Bolton, R., \& Wagner, J. (1999). A model of customer satisfaction with service encounters involving failure and recovery. Journal of Marketing Research, 36, 356-372. 
Sparks, B. A., \& Callan, V. J. (1996). Service breakdowns and service evaluations: The role of customer attributions. Journal of Hospitality and Leisure Marketing, 4(2), 3-24.

Sparks, B. A., \& McColl-Kennedy, J. R. (2001). Justice options for increased customer satisfaction in a services recovery setting. Journal of Business Research, 54, 209-218.

Swan, J. E., \& Combs, L. J. (1976). Product performance and consumer satisfaction. Journal of Marketing, 40, 25-33.

Tax, S. S., Brown, S. W., \& Chandrashekaran, M. (1998). Customer evaluations of service complaint experiences: Implications for relationship marketing. Journal of Marketing, 62, 60-76.

Thibaut, J., \& Walker, L. (1975). Procedural justice: A psychological analysis. Hillsdale, NJ: Lawrence Erlbaum.

Van den Bos, K., Bruins, J., Wilke, H. A. M., \& Dronkert, E. (1999). Sometimes unfair procedures have nice aspects: On the psychology of the fair process effect. Journal of Personality and Social Psychology, 77, 324-336.

Webster, C., \& Sundaram, D.S. (1998). Service consumption criticality in failure recovery. Journal of Business Research, 41, 153-159.

Widmier, S., \& Jackson, D. W. (2002). Examining the effects of service failure, customer satisfaction, and fault on customer satisfaction with salespeople. Journal of Marketing Theory and Practice, 10(1), 63-73.

Willson, P., \& McNamara, J. R. (1982). How perceptions of a simulated physicianpatient interaction influence intended satisfaction and compliance. Social Science and Medicine, 16, 1699-1704. 
Author Note

Kate Worsfold, Jennifer Worsfold and Graham L. Bradley are with the School of Psychology and the Service Industry Research Centre, Griffith University, Queensland, Australia.

This research was completed as part of the first two authors' graduate studies, under the supervision of the third author.

Correspondence should be addressed to Dr Graham Bradley, Service Industry Research Centre and School of Psychology, Griffith University, PMB 50 Gold Coast Mail Centre, Queensland 9726, Australia. Email: g.bradley@griffith.edu.au 
Table 1

Descriptive Statistics and Correlations for Study 1 Dependent Variables

\begin{tabular}{|c|c|c|c|c|c|}
\hline \multirow{2}{*}{ Variable } & \multirow{2}{*}{ Mean } & \multirow{2}{*}{ SD } & Alpha & \multicolumn{2}{|c|}{ Correlations } \\
\hline & & & Reliability & 1 & 2 \\
\hline 1. Satisfaction & 4.73 & 1.25 & .91 & & \\
\hline 2. Repatronage Intentions & 5.27 & 1.20 & .89 & $.76 * * *$ & \\
\hline 3. Complaint Intentions & 3.56 & 1.51 & .89 & $-.59 * * *$ & $-.64 * * *$ \\
\hline
\end{tabular}


Table 2

Summary of Study 1 MANOVA Results

\begin{tabular}{|c|c|c|c|c|c|}
\hline \multirow[t]{2}{*}{ Source } & \multicolumn{2}{|c|}{$\begin{array}{l}\text { Multivariate } \\
(d f=3,169)\end{array}$} & \multicolumn{3}{|c|}{$\begin{array}{l}\text { Univariate } \\
(d f=1,171)\end{array}$} \\
\hline & $F$ & partial $\eta^{2}$ & Outcome & $F$ & $\operatorname{partial} \eta^{2}$ \\
\hline \multirow[t]{3}{*}{ Rapport (R) } & $31.76^{* * *}$ & .361 & Satisfaction & $86.02 * * *$ & .335 \\
\hline & & & Repatronage & $30.86^{* * *}$ & .153 \\
\hline & & & Complaint & $6.30 *$ & .036 \\
\hline \multirow[t]{3}{*}{ Compensation (C) } & $4.72 * *$ & .077 & Satisfaction & $13.42 * * *$ & .073 \\
\hline & & & Repatronage & $7.43^{*}$ & .042 \\
\hline & & & Complaint & $8.07 *$ & .045 \\
\hline \multirow[t]{3}{*}{ Failure Type (T) } & $32.89 * * *$ & .369 & Satisfaction & $14.21 * * *$ & .077 \\
\hline & & & Repatronage & $17.65 * * *$ & .094 \\
\hline & & & Complaint & $95.44 * * *$ & .358 \\
\hline \multirow[t]{3}{*}{$\mathrm{R} \times \mathrm{C}$} & $5.38 * *$ & .087 & Satisfaction & $7.39 *$ & .041 \\
\hline & & & Repatronage & 0.43 & .002 \\
\hline & & & Complaint & 0.79 & .005 \\
\hline \multirow[t]{3}{*}{$\mathrm{R} \times \mathrm{T}$} & $3.40 *$ & .057 & Satisfaction & $7.98 *$ & .045 \\
\hline & & & Repatronage & $8.99 * *$ & .050 \\
\hline & & & Complaint & 4.82 & .027 \\
\hline $\mathrm{C} \times \mathrm{T}$ & 2.18 & .037 & & & \\
\hline $\mathrm{R} \times \mathrm{C} \times \mathrm{T}$ & 1.17 & .020 & & & \\
\hline
\end{tabular}


Table 3

Descriptive Statistics and Correlations for Study 2 Dependent Variable

\begin{tabular}{lccccc}
\hline \multicolumn{1}{c}{ Variable } & Mean & SD & $\begin{array}{c}\text { Alpha } \\
\text { Reliability }\end{array}$ & \multicolumn{2}{c}{ Correlations } \\
& & & & & 2 \\
\hline 1. Satisfaction & 4.73 & 1.16 & .90 & & \\
2. Repatronage Intentions & 4.98 & 1.18 & .87 & $.74 * * *$ & \\
3. Complaint Intentions & 2.82 & 1.12 & .83 & $-.59 * * *$ & $-.49 * * *$ \\
$* * * p<.001$. & & & & &
\end{tabular}


Table 4

Summary of Study 2 MANOVA Results

\begin{tabular}{|c|c|c|c|c|c|}
\hline \multirow{3}{*}{ Source } & \multirow{2}{*}{\multicolumn{2}{|c|}{$\begin{array}{l}\text { Multivariate } \\
(d f=3,169)\end{array}$}} & \multirow{2}{*}{\multicolumn{3}{|c|}{$\begin{array}{l}\text { Univariate } \\
(d f=1,171)\end{array}$}} \\
\hline & & & & & \\
\hline & $F$ & partial $\eta^{2}$ & Outcome & $F$ & partial $\eta^{2}$ \\
\hline \multirow[t]{3}{*}{ Rapport (R) } & $26.76^{* * *}$ & .322 & Satisfaction & $36.90 * * *$ & .177 \\
\hline & & & Repatronage & $68.87 * * *$ & .287 \\
\hline & & & Complaint & 0.35 & .002 \\
\hline \multirow[t]{3}{*}{ Compensation (C) } & $13.96 * * *$ & .199 & Satisfaction & $22.96 * * *$ & .118 \\
\hline & & & Repatronage & $38.93 * * *$ & .185 \\
\hline & & & Complaint & 3.07 & .018 \\
\hline \multirow[t]{3}{*}{ Failure Severity (S) } & $56.34 * * *$ & .500 & Satisfaction & $133.23 * * *$ & .438 \\
\hline & & & Repatronage & $122.67 * * *$ & .418 \\
\hline & & & Complaint & $62.86^{* * *}$ & .269 \\
\hline \multirow[t]{3}{*}{$\mathrm{R} \times \mathrm{C}$} & $5.21 * *$ & .085 & Satisfaction & 4.13 & .024 \\
\hline & & & Repatronage & $11.98 * *$ & .065 \\
\hline & & & Complaint & 0.35 & .002 \\
\hline \multirow[t]{3}{*}{$\mathrm{R} \times \mathrm{S}$} & $4.34 * *$ & .072 & Satisfaction & 0.50 & .003 \\
\hline & & & Repatronage & $6.70 *$ & .038 \\
\hline & & & Complaint & 2.67 & .015 \\
\hline $\mathrm{C} \times \mathrm{S}$ & 0.77 & .014 & & & \\
\hline \multirow[t]{3}{*}{$\mathrm{R} \times \mathrm{C} \times \mathrm{S}$} & $5.04 * *$ & .082 & Satisfaction & 0.17 & .001 \\
\hline & & & Repatronage & $7.01 *$ & .039 \\
\hline & & & Complaint & $6.71 *$ & .038 \\
\hline
\end{tabular}

